\title{
Non-immune hydrops fetalis
}

INSERM

\section{Source}

INSERM. (1999). Orphanet: an online rare disease and orphan drug data base. Nonimmune hydrops fetalis. ORPHA:363999

Non-immune hydrops fetalis (NIHF), a form of $\mathrm{HF}$, is a severe fetal condition defined as the excessive accumulation of fetal fluid within the fetal extravascular compartments and body cavities, and is the end-stage of a wide variety of disorders. 